Haya: The Saudi Journal of Life Sciences

Abbreviated Key Title: Haya Saudi J Life Sci

ISSN 2415-623X (Print) |ISSN 2415-6221 (Online)

Scholars Middle East Publishers, Dubai, United Arab Emirates

Journal homepage: https://saudijournals.com

Review Article

\title{
Harmful and Beneficial Effect of Senna Makki in COVID-19
}

\author{
Irum Naureen $^{1 *}$, Aisha Saleem ${ }^{2}$, Ayesha Shahid ${ }^{2}$, Qaisera Tasneem ${ }^{2}$, Ansa Tariq ${ }^{2}$, Asia Hassan $^{2}$, Asia Bibi $^{2}$ \\ ${ }^{1}$ Assistant Professor, School of Zoology, Minhaj University Lahore, Pakistan \\ ${ }^{2}$ M. Phil Researcher, School of Zoology, Minhaj University Lahore, Pakistan
}

DOI: $\underline{10.36348 / \mathrm{sj} 1 \mathrm{l} .2022 . \mathrm{v} 07 \mathrm{i} 01.003}$

| Received: 09.12.2021 | Accepted: 20.01.2022 | Published: 24.01.2022

*Corresponding author: Irum Naureen

Assistant Professor, School of Zoology, Minhaj University Lahore, Pakistan

\section{Abstract}

The outbreak of the unconventional coronavirus (SARS-CoV-2) on account that December 2019 has created an extraordinary state. Senna is a type of plant in the tropics. Senna, the sienna's, is a huge variety of blossoming plants in the vegetable family (Fabaceae, subfamily Caesalpinioideae, clan Cassia). As It is a brand new variation of a deadly disease remedy alternatives aren't simplest confined however require painstaking trials to verify theireffectiveness. Due to the lack of information in lots of growing international locations, humans have begun out the usage of herbalmedications, used for numerous different diseases, to fight COVID-19. Misleading data on social mediaregarding "Senna Makki" has gone microorganism in the Asian nation. However, consumption of bush Makki isn't suggested as atreatment possibility for COVID-19 thanks to its several harmful associated side-effects. Though its use in different diseases isevident, trials to verify its effectiveness against COVID-19 got to be prioritized because the public has startedconsuming bush Makki in high doses and while not monitoring prescript.

Keywords: COVID-19, SARS-COV-1, SARS-COV2, Medicinal plants.

Copyright ( $) 2022$ The Author(s): This is an open-access article distributed under the terms of the Creative Commons Attribution 4.0 International License (CC BY-NC 4.0) which permits unrestricted use, distribution, and reproduction in any medium for non-commercial use provided the original author and source are credited.

\section{INTRODUCTION}

The Coronavirus sickness 2019 (COVID-19) could be a severe acute metabolic process syndrome caused by coronavirus a pair of (SARS-CoV-2). COVID-19 was declared a world wide pandemic all around the world on the eleventh of March 2020 by the planet health organization (WHO) [1]. Senna, the sienna's, is a huge variety of blossoming plants in the vegetable family (Fabaceae, subfamily Caesalpinioideae, clan Cassia). This different class is local all through the jungles, with few species in mild areas. The quantity of species is assessed to be from around 260 to 350 . The sort species for the class is Sienna Alexandrina. Around 50 types of Sana are known in development. ). Senna is a type of plant in the tropics [3]. The leaves of the Senna plant have been used for a laxative action by pediatricians, pediatric surgeons, and pediatric gastroenterologists [4].

The severe acute metabolic process syndrome Coronavirus a pair of (SARS-CoV-2) originated within the town of metropolis in China, wherever the primary case of COVID-19 was reported in Gregorian calendar month 2019 [2]. However, because of its fast transmission, SARS-CoV-2 was able to unfold its roots to alternative neighboring countries as well. USA, Brazil, India, Russia, Republic of South Africa, Peru, and Mexico.one among the potential causes for such fast transmission to alternative countries was frequent domestic and international travel. It's been well established that COVID-19 spreads through metabolic process droplets from associate degree infected person, once the person coughs, sneezes or speaks, or by touching a contaminated surface then touching the eyes, mouth, or nose, before laundry hands. The most common symptoms of COVID-19, shortness of breath, weariness including fever, cough, fatigue or myalgia and atypical symptoms include hemoptysis, diarrhea, headache and sputum. ${ }^{[2]}$ Other symptoms include lymphocytopenia and all patients had pneumonia which can cause COVID-19. The complete sequence of SARS-2 has been obtained and disease can be diagnosed by RT- PCR and sample is collected from either lower or upper respiratory tract or by counting the total number of leukocyte and lymphocytes [3, 4].

In December 2019, a pandemic of severe acuterespiratory syndrome coronavirus 2 (SARS-CoV2) infections occurred in Wuhan, Hubei Province, 
Irum Naureen et al., Haya Saudi J Life Sci, Jan, 2022; 7(1): 13-18

China, and spread across China and beyond. On February 12, 2020, the WHO officially named the disease caused bythe novel coronavirus as Coronavirus Disease 2019(COVID-19) It isestimated that in $70 \%$ of patients the disease isasymptomatic or with very mild symptoms, while theremaining $30 \%$ of patients suffer from a respiratorysyndrome associated with high fever and cough. Insome cases, this may progress to respiratory failureand the patient may require ICU admission [5]. Thereis no specific antiviral treatment recommended forCOVID-19, and no vaccine is currently available. Symptomatic treatment is encouraged and for patientswith respiratory impairments, oxygen therapy is effective pharmacologic treatment against COVID-19 [17, 36].

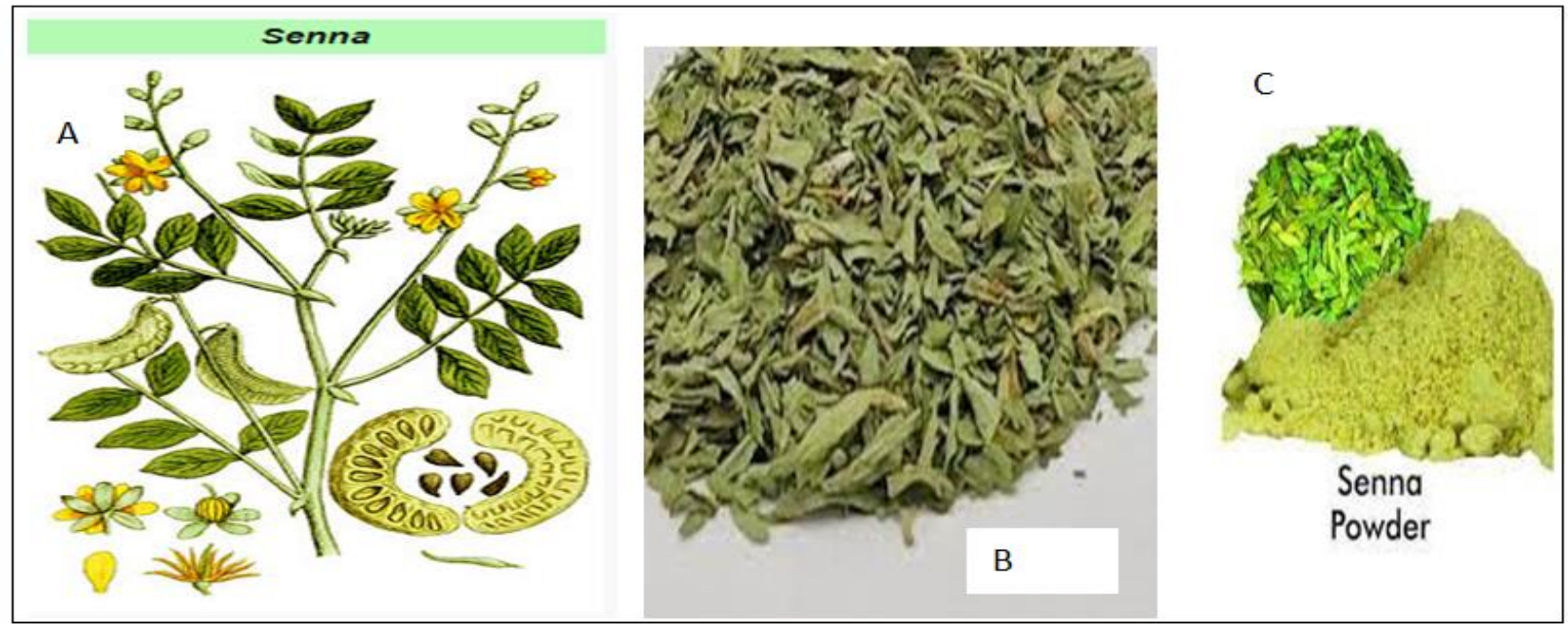

Fig 1: A) Senna makki plant; B) Senna makki leaves; C) Senna makki powder [5, 29]

\section{COVID- 19 AND MYTHS}

As the COVID-19 virus is novel there have been myriad ambiguities relating to potential cure and treatment, and lots of researchers worldwide square measure in a constant struggle to see a treatment for this virus [8]. To date, there's no immunizing agent offered for COVID-19, and several treatment choices square measure being checked out the several treatment choices square measure being checked out by the researchers and aid staff thanks to hugepanic, shock, and concern created among the general public, people native to central and northern components of Sudan and Sinai and is cultivated beside the watercourse river, whereas Cassia Angustifolia is native to an African country and Southern Arabia, and is cultivated within the North-West of Pakistan and the Southern Republic of India [9]. The type of bush that herbalists use in Indo-Pak and Arabian countries is Cassia angustiwhicha, which is listedunder the name of "Senna Makki” [22].

Use and mode of action of Senna Makki [15]

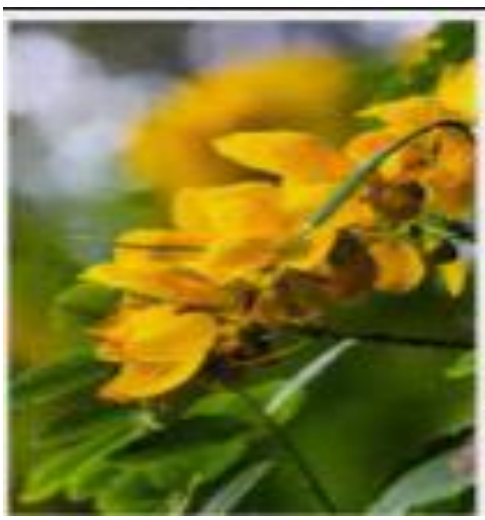

The United States Food and drug administration (FDA) has allowed Senna Makki to be used as an over counter drug. It is used for digestive disorders, such aschronic constipation, hemorrhoids, irritable bowelsyndrome, weight loss, and for other illnesses, such asdepression, asthma, eczema, and other

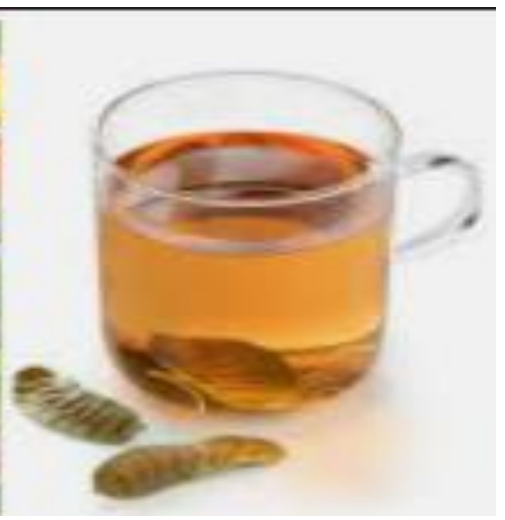

dermatological conditions [15]. Senna Makki is known for its strongconditions. Senna Makki is known for its stronglaxative effect and is most commonly used in thetreatment of chronic constipation. It contains anthracites, derivatives, such as sennosides, which on hydrolysis bybacterial enzymes in the gut, release 
Irum Naureen et al., Haya Saudi J Life Sci, Jan, 2022; 7(1): 13-18

glycines of three types; namely anthraquinones, anthrenthralls. Oxantxanthones These glycines are the active part ofsennoside and cause laxative action by influencing the transport of water and electrolytes [11].

\section{CHEMICAL COMPOSITION OF SANNA MAKKI:

\begin{tabular}{|ll|}
\hline \multicolumn{2}{|l|}{ CHEMICAL CONSTITUENTS } \\
\hline 1. Rhein & 6. Kaempferol \\
2. Aloe-emodin & 7. Isorhamnetin \\
3. Myricyl alcohol & 8. phytosterol \\
4. Salicylic acid & 9. Mucilage \\
5. Resin & 10. Cacium oxalate \\
\hline
\end{tabular}

The dried leaves and fruits of the bush area unit are used formedicinal functions. There are unit forms of the ush, themost common one being the tinnevelly Senna that originates from Egypt and is additionally called "Alexandrian Senna [8]. Cass Angustifoliaais that the second most common style of bush that originates from Asian nation and is known as "Tinnevelly Senna" $[9,10]$. Tinnevelly Senna is native to central and northern and is cultivated beside the watercourse Nile, whereas CassiaAngustifolia is native to Somalia and Southern Arabian Peninsula, and is cultivated within the North-West of Asian countries and Southern Asian countries.10the type of bush that herbalists use in Indo-Pak and Arabian In China, traditional herbal treatment was also adopted against COVID-19 and has shown good result [12].

\section{Contraindication and drug-drug interaction of Senna Makki}

The counseled dose of bush Makki is eight.5 mg per dayfor youngsters, $17.2 \mathrm{mg}$ per day with no thirty-four ours. 4 mgfor children over twelve and adults twenty-eighth mg per dayfor children over twelve and adults twenty-eighth $\mathrm{mg}$ per dayIts consumption is contraindicated in youngsters but a pair ofyears mature and patients with enteropathyulcerative rednesCrohn'sn's unwellness, rubor, dehydration, symptom and heart diseases [14]. Also, the have as been noticeable drug interactions of bush Makki inpeople that use contraceptives (vaginal ring, patch, andpills), digoxin, warfare, diuretics, estrogens, horsetail herb and licorice [28].

The elements of shrub Makki work as a robustlaxative and will irritate the bowbowelnings, which suggests itcan irritate the symptoms of these patients littered with COVID-19, World Health Organization might also suffer from looseness of the bowels andnausea, that area unit COVID-19 symptoms. However, due toits exaggerated promotion for effectiveness against COVID19, ${ }^{[15]}$ it shortly became the chalice in the Islamic Republic of Pakistan for COVID19 treatment and other people started victimization excess quantity. The drug while not deliberating its risks and facet affects overit's edges
[21]. The very fact that it will cause severe dehydration and associate solution imbalance which may be fatal, alongwith abdominal pain, cramping, fainting, and discomfort was unheeded [23].

Nursing mothers should consult a healthcare professional as constituents of Senna Makki can pass intobreast milk in smaller amounts, however, if taken in affect nursing baby's feces its safety in pregnant women are yet to be confirmed [34].

\section{Senna Makki and COVID-19 in Pakistan}

People in Asia countries were greatly influenced by the claim of a UK-based-herbalist UN agency reportable spoken communication that hetreated concerning a hundred and fifty COVID-19 affected patients by prescribing them bush Makki, and this was additionallysupported by the governor of Sindh, Pakistan [18]. The general public of Asian count countries began exploitation. It absolutely was reportable by the media that Senna Makki, that accustomed be oversubscribed at PKR three hundred $/ \mathrm{kg}$, was now merchandising for PKR one, 500$2,000 / \mathrm{kg}$. ${ }^{[32]}$ There is still a significant difference over the usage of bushMakki as a cure for COVID-19. Pakistani health consultants strongly urged the general public to avoid bush Makki, stating that there are not any clinical trials or studies that ensure the effectiveness of bush Makki in treating COVID-19 [16] Anthraquinone is reported to have medicament, antiviral and immune-boosting role [17]. Senna Makki and lack of clinical data, health care professional's havestrongly discouraged its use in COVID-19. The use of natural plants as medicines was started in ancient times. Hazrat Muhammad (SAW) used a number of plants and plant products for the treatment of many diseases in His life [24].

\section{Medicinally benefits of Senna Makki}

The Plant having medicinal importance mentioned in the Holy Quran and Hadith, and the identification of active phytochemicals having antiviral properties that can be used for the cure of respiratory and other contagious viral diseases including COVID$19[7,14]$. 

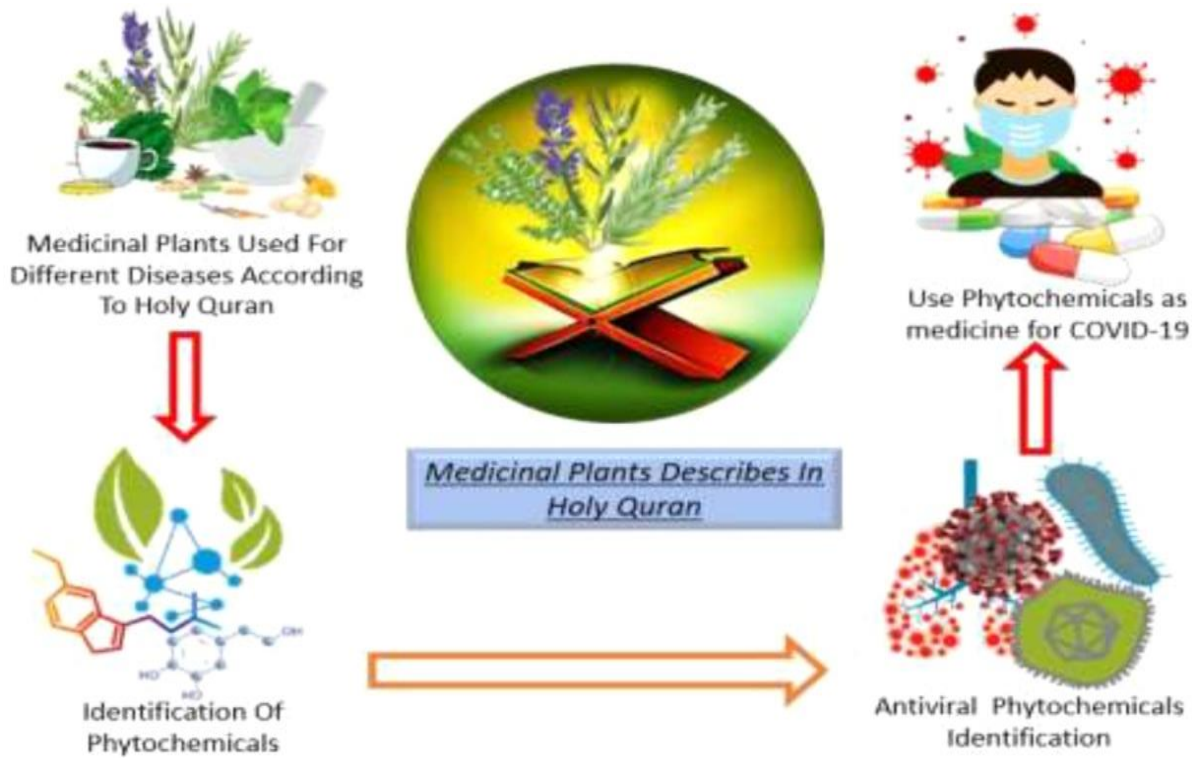

Fig 2: Senna makki use for the cure of COVID-19 [9]

\section{Boosts Immunity}

Skin aggravations like psoriasis, skin inflammation, dermatitis, and pimples should have an admission of Sana Makki. It is on the grounds that the glue which is made of Alexandria Senna when applied to the skin can assist with disposing of any of these disturbances [27]. Also, the Sana Makki has an antibacterial component so it supports the insusceptible framework and assists with battling against any of these aggravations. Likewise, in this COVID19 condition, we really want to supports our safe framework [35].

\section{Weight Loss}

It helps in weight reduction thus; it is awesome for those you are making a decent attempt to lose their weight. Its low-calorie flavorsome arrangement expands the admission of fluid and it advances the fiber which fixes the issue of stoppage. The purging capacity of it detoxifies the body [26].

\section{Strengthens the Hair:}

Senna Makki is beneficial for Hairs. Citrus components and natural components, that is beneficially giving good results. Sana Makki battles with going bald as well. It volumizes the hair and gives the hair the ideal definition [17].

\section{Helps In Digestion}

It helps in giving alleviation from indigestion, queasiness, gas, bulging, and burping. It is ideal to manage stomach related issues [29].

\section{Disadvantages of Senna Makki}

Senna makki side effects can be harsh for those patients already in critical conditions. There have been many reported interactions of Senna with many drugs and it is not suited for heart, liver and kidney patients. Cause unusual stomach throb, burping, spasms, weighty retching, an increment of protein in
Urine, and unusual pee with blood (in some cases). WHO has encouraged the clinical investigations to find safe and effective herbs in the treatment of COVID-19 [30], Senna leaves may not be used for the prophylaxis or treatment of COVID-19 without having any sufficient clinical data as the drug is potent laxative and can raise the complications of COVID-19 patients instead of benefits by augmenting diarrhea and other gastrointestinal problems [32].

\section{Hazard Factors}

The Senna Leaves can be extremely hazardous as well on the off chance that it is utilized for a more extended time frame. ${ }^{[31]}$ The danger factors are: the spice might prompt staining of the spice additionally, the inward covering of the digestive tract might become dark, lack of potassium in the blood, skin sensitivities, rashes, debilitates the bones might prompt Arthritis as well, it relax the bones as well, and so on Assuming you are pregnant then try not to take it [13].

\section{CONCLUSION}

It is crucial that the public strongly follow their healthcare provider's recommendations, direction, and preventative guidelines for COVID-19. As an urgent measure to control COVID-19 and its further exacerbations of Disease, the general public is advised to avoid self-treating with medicines and herbs which they assume might have a potential role in curing COVID-19, unless it is proven by clinical trials and studies. As in evidence-based medicine, clinical trials play a pivotal role in determining the effectiveness of a particular treatment for a disease. Hence, there is a critical and necessary need for additional clinical studies that can assess the potential role of Senna Makki in treating Covid-19. 
Irum Naureen et al., Haya Saudi J Life Sci, Jan, 2022; 7(1): 13-18

\section{REFERENCES}

1. WHO Director-General's Opening Remarksat the Media Briefing on COVID19-March 2020.

2. Huang, C., Wang, Y., Li, X., Ren, L., Zhao, J., Hu, Y., ... \& Cao, B. (2020). Clinical features of patients infected with 2019 novel coronavirus in Wuhan, China. The lancet, 395(10223), 497-506.

3. Fadzureena, J., Mazura, M. P., Adiana, M. A., \& Hani, I. B. (2013). An investigation into the inhibitory effect of Senna alata L. leaf extract as well as its isolated compound on xanthine oxidase assay. Proceedings of the Conference on Forestry and Forest Products Research (Kuala Lumpur), 262.

4. Vilanova-Sanchez, A., Gasior, A. C., Toocheck, N., Weaver, L., Wood, R. J., Reck, C. A., Wagner, A., Hoover, E., Gagnon, R., \& Jaggers, J. (2018). Are Senna based laxatives safe when used as long term treatment for constipation in children? Journal of Pediatric Surgery, 53(4), 722-727.

5. Ghanem, M. T., Tawfik, W. A., Mahdy, E. S. M., Abdelgawad, M. E., Abdel-Azim, N. S., \& ElMissiry, M. M. (2019). Chemical and biological evaluation of olive leaves as a waste by-product of olive oil industry. Egyptian Pharmaceutical Journal, 18(2), 172.

6. Wu, F., Zhao, S., Yu, B., Chen, Y. M., Wang, W., Song, Z. G., ... \& Zhang, Y. Z. (2020). A new coronavirus associated with human respiratory disease in China. Nature, 579(7798), 265-269.

7. Jin, Y. H., Cai, L., Cheng, Z. S., Cheng, H., Deng, T., Fan, Y. P., ... \& Wang, X. H. (2020). A rapid advice guideline for the diagnosis and treatment of 2019 novel coronavirus (2019-nCoV) infected pneumonia (standard version). Military Medical Research, 7(1), 1-23.

8. Sharma, A., Sharma, S. K., Shi, Y., Bucci, E., Carafoli, E., Melino, G., ... \& Das, G. (2020). BCG vaccination policy and preventive chloroquine usage: do they have an impact on COVID-19 pandemic?. Cell death \& disease, 11(7), 1-10.

9. Ahmad, M., Khan, M. A., Marwat, S. K., Zafar, M., Khan, M. A., Hassan, T. U., \& Sultana, S. (2009). Useful medicinal flora enlisted in Holy Quran and Ahadith. Am Eurasian J Agric Environ Sci, 5(1), 126-140.

10. Yang, L., \& Tu, L. (2020). Implications of gastrointestinal manifestations of COVID-19. The Lancet Gastroenterology \& Hepatology, 5(7), 629630.

11. Hietala, P., Marvola, M., Parviainen, T., \& Lainonen, H. (1987). Laxative potency and acute toxicity of some anthraquinone derivatives, senna extracts and fractions of senna extracts. Pharmacology \& toxicology, 61(2), 153156.

12. Shah, V. K., Firmal, P., Alam, A., Ganguly, D., \& Chattopadhyay, S. (2020). Overview of Immune Response During SARS-CoV-2 Infection: Lessons From the Past. Front Immunol, 11, 19-25.
13. DAWN. News. Available at: https://www.dawn.com/news/1557883. Accessed on25 August 2020.

14. Sultana, S., Ahmad, M., Zafar, M., Khan, M. A., \& Arshad, M. (2012). Authentication of herbal drug Senna (Cassia angustifolia Vahl.): A village pharmacy for Indo-Pak Subcontinent. African journal of pharmacy and pharmacology, 6(30), 2299-2308.

15. Hussain, I., Zin, C. S., Malik, E., \& Raza, M. S. (2020). Associated Harms with Usage of Senna Leaves (Sana Makki) in Covid-19. RADS Journal of Pharmacy and Pharmaceutical Sciences, 8(1), 63-64.

16. Naz, H., Nawaz, H., Hanif, M. A., Ayub M. A., \& Khatun, S. (2020). Indian Senna., In Medicinal plants of South Asia. Amsterdam: Elsevier, 33, 439-449.

17. Kumar, S., Naeem, R., Radhawi, A. S. T., Mahmood, S. U., Batool, Z., \& Naqi, S. R. A. (2020). Senna Makki and the COVID-19 pandemic: a reflection from Pakistan. International Journal of Community Medicine and Public Health, 7(12), 5194.

18. World Health Organization. (30 April 2020). Coronavirus disease 2019 (COVID-19): Situation Report, 101.

19. Wu, Q. P., Wang, Z. J., Fu, M. H., Tang, L.Y., He, Y., Fang, J., \& Gong, Q. F. (2007). Chemical constituents from the leaves of Cassia angustifolia. Zhong yao cai $=$ Zhongyaocai $=J$. Chinese Med. Mater, 30(10), 1250-1252.

20. Cascella, M., Rajnik, M., Aleem, A., Dulebohn, S., \& Di Napoli, R. (2021). Features, evaluation, and treatment of coronavirus (COVID-19). StatPearls.

21. Hard castle, J. D., \& Wilkins, J. L. (1970). The action of sennosidesand related compounds on the human colon and rectum, Gut, 11(12), 1038-1042.

22. Miller, A., Reandelar, M. J., Fasciglione, K., Roumenova, V., Li, Y., \& Otazu, G. H. (2020). Correlation between universal BCG vaccination policy and reduced mortality for COVID19. MedRxiv.

23. Faust, L., Huddart, S., MacLean, E., \& Svadzian, A. (2020). Universal BCG vaccination and protection against COVID-19: a critique of an ecological study. J Club Coronavirus past Prese Futu, 1-8

24. Franz, G. (1993). The senna drug and its chemistry. Pharmacology, 47(1), 2-6.

25. Hard castle, J. D., \& Wilkins, J. L. (1970). The action of sennosidesand related compounds on the human colon and rectum, Gut, 11(12), 1038-1042.

26. Duncan, A. S. (1957). Standardized senna as a laxative in the Puerperium. British medical journal, 1(5016), 439-441.

27. Spiller, H. A., Winter, M. L., Weber, J. A., Krenzelok, E. P., Anderson, D. L., \& Ryan, M. L. (2003). Skin breakdown and blisters from senna- 
Irum Naureen et al., Haya Saudi J Life Sci, Jan, 2022; 7(1): 13-18

containing laxatives in young children. Annals of Pharmacotherapy, 37(5), 636-639.

28. Kinnunen, O., Winblad, I., Koistinen, P., \& Salokannel, J. (1993). Safety and efficacy of a bulk laxative containing senna versus lactulose in the treatment of chronic constipation in geriatric patients. Pharmacology, 47(Suppl. 1), 253-255.

29. Hietala, P., Marvola, M., Parviainen, T., \& Lainonen, H. (1987). Laxative potency and acute toxicity of some anthraquinone derivatives, senna extracts and fractions of senna extracts. Pharmacology \& toxicology, 61(2), 153156.

30. Lemli, J. (November 1995). Mechanism of action of sennosides, Bulletin de l'Académie Nationale de Médecine, 179(8), 1605-1611.

31. Qamar, M., Alqahtani, S., Alamri, M., \& Chen, L. (2020). Structural basis of SARS-CoV-2 3CLpro and anti-COVID-19 drug discovery from medicinal PLANTS. Preprints, 2020030455.
32. Wald, A. (2016). Constipation: advances in diagnosis and treatment. Jama, 315(2), 185-191.

33. Khare, C. P. (2004). Indian Herbal Remedies Rational Western Therapy, Ayurvedic and Other Traditional Usage, Botany. Berlin, Heidelberg: Springer Berlin Heidelberg, 32, 12-18.

34. Franz, G. (October 1993). The Senna drug and its chemistry. Pharmacology, 47, 2-6. Doi: 10.1159/000139654. PMID 8234429.

35. Vishal, V., Ganesh, S., Mukesh, G., \& Ranjan, B. (2014). A review on some plants having antiinflammatory activity. $J$ Phytopharmacol,3(3), 214-21-221.

36. Kumar, S., Naeem, R., Radhawi, A. S. T., Mahmood, S. U., Batool, Z., \& Naqi, S. R. A. (2020). Senna Makki and the COVID-19 pandemic: a reflection from Pakistan. International Journal of Community Medicine and Public Health, 7(12), 5194-5197. 